\title{
Educação em tempo integral no Brasil: rupturas, avanços, permanências e desafios de uma política pública no contexto escolar
}

\author{
Full time education in Brazil: ruptures, advances, permanencies and challenges of a public policy in the \\ school context
}

L'éducation à temps plein au Brésil: ruptures, avancées, permanences et défis d'une politique publique dans le contexte scolaire

Entrevista: Lúcia Velloso Maurício

Ediléia Alves Mendes Souza ${ }^{1}$

Universidade Estadual de Montes Claros

Gabriel Humberto Muñoz Palafox ${ }^{2}$

Universidade Federal de Uberlândia

Maria Vieira Silva ${ }^{3}$

Universidade Federal de Uberlândia

Robson Luiz de França ${ }^{4}$

Universidade Federal de Uberlândia

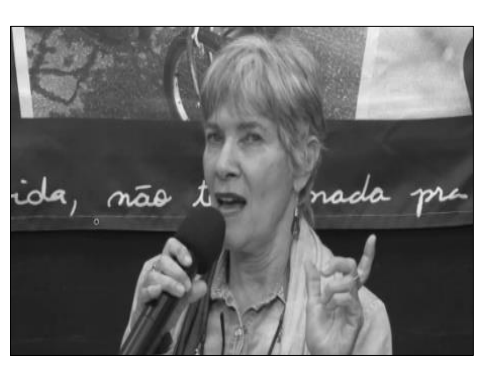

Lúcia Velloso Maurício: Doutora em Educação pela Universidade Federal do Rio de Janeiro (UFRJ), fez pós-doutorado na Universidade Complutense de Madri e na Universidade do Estado do Ceará (UECE). É professora associada da Faculdade de Formação de Professores da Universidade do Estado do Rio de Janeiro (UERJ). Participou do processo de implantação dos Centros Integrados de Educação Pública (CIEP) e atuou como consultora e conselheira da Fundação Darcy Ribeiro. É membro e uma das fundadoras do NEEPHI - Núcleo de Estudos de Tempos, Espaços e Educação Integral, sediado na Unirio. Pesquisa o tema há mais de trinta anos.

\footnotetext{
${ }^{1}$ Doutora em Educação pela UFU, Mestre em Educação pela UnB. Professora do DMTE/Unimontes, com atuação, sobretudo no Curso de Pedagogia e outras licenciaturas. E-mail: edileia_mendes@yahoo.com.br. ORCID: https://orcid.org/0000-0001-9369-2453. Lattes: http://lattes.cnpq.br/4349292205055105.

${ }_{2}^{2}$ Doutor em Educação e Currículo pela PUC-São Paulo. Professor Titular da Universidade Federal de Uberlândia UFU, lotado na Faculdade de Educação Física - FAEFI, professor permanente do Programa de Pós-graduação em Educação da UFU, membro da linha de pesquisa em Políticas e Gestão da Educação.E-mail: gabmpalafox@hotmail.com. ORCID: https://orcid.org/0000-0002-9295-560X . Lattes: http://lattes.cnpq.br/9156400785591228

${ }^{3}$ Doutora em Educação pela Universidade Estadual de Campinas com estágio de pós-doutorado realizado no Centre de Recherches Sociologiques e Politiques de Paris - Université Paris VIII. Professora Titular de Políticas e Gestão da Faculdade de Educação da Educação da Universidade Federal de Uberlândia. Bolsista de Produtividade em Pesquisa do CNPq. Coordenadora do Grupo de Pesquisa Polis, Políticas Educação e Cidadania - UFU. Diretora de Formação e Desenvolvimento da Associação Nacional de Política e Administração da Educação - ANPAE. Membro do Grupo de Trabalho Estado e Políticas Educacionais da ANPED e membro do Centro de Estudos Educação e Sociedade - CEDES. E-mail: mvieiraufu@ufu.br. ORCID: https://orcid.org/0000-0002-4510-0844. Lattes: http://lattes.cnpq.br/0726794592785841.

${ }_{4}^{4}$ Pós-doutor em Política Educacional pela Universidade Federal da Paraíba e Universidade de Portugal - PT. Doutor em Educação pela Universidade Júlio Mesquita Filho - UNESP/Araraquara. Professor da Faculdade de Educação da Universidade Federal de Uberlândia, com atuação na graduação e na Pós-graduação, membro da linha de pesquisa Trabalho, Sociedade e Educação. E-mail: robson.l.franca@gmail.com. ORCID: https://orcid.org/0000-0001-7966961X. Lattes: http://lattes.cnpq.br/6494919511957208
} 
Resumo: Na presente entrevista, por meio do diálogo estabelecido com uma professora engajada na luta em defesa da educação pública, propõe-se a fazer uma análise a respeito da educação integral em tempo integral. Para tal abordou-se alguns dos principais aspectos que influenciam na implementação e desenvolvimento dessa política no contexto escolar brasileiro. As reflexões contribuem para fomentar a crítica em torno de concepções vigentes, da estrutura, da legislação, ressaltando-se rupturas, avanços e lacunas que ainda persistem. $\mathrm{O}$ balanço analítico em torno da experiência dos Ciep, no Rio de Janeiro nas décadas de 1980/1990, coloca em discussão os limites e desafios dessa política e ao mesmo tempo resgata-a enquanto possibilidade de melhoria do ensino público promovendo maior igualdade educacional visto que permite ampliar as experiências formativas dos alunos, sobretudo das camadas populares.

Palavras chave: Educação em Tempo Integral. Política Pública Educacional. Contexto Escolar.

Abstract: In this interview, through the dialogue established with a teacher engaged in the fight in defense of public education, it is proposed to make an analysis about full-time full education. For such, we addressed some of the main aspects that influence the implementation and development of this policy in the Brazilian school context. The reflections contribute to promote the criticism about current conceptions, the structure, the legislation, highlighting ruptures, advances and gaps that still persist. The analytical balance on the experience of the Ciep in Rio de Janeiro in the 1980s and 1990s brings into discussion the limits and challenges of this policy and at the same time rescues it as a possibility of improving public education by promoting greater educational equality since It allows to broaden the formative experiences of the students, especially the popular classes.

Key words: Full time education. Educational Public Policy. School context.

Resumé: Dans cet entretien, parmi d’un dialogue établi avec une professeur engagée dans la lutte pour la défense de l'éducation publique, elle est proposé de faire une analyse sur l'éducation complète à temps plein. Pou cela, nous avons abordé certains des principaux aspects qui influencent sur la mise en ouvre et développement de cette politique dans le contexte scolaire brésilien. Les réflexions contribuent à promovoir la critique autour des conceptions actuelles, de la structure, de législation en soulignant les ruptures, les avancées et les lacunes qui persistent. La balance analytique autour de l'expérience du Ciep, à Rio de Janeiro dans les décennies 1980/1990, remet em question les limites et les défis de cette politique tout en la préservant comme une possibilité d'améliorer l'éducation publique en promouvant une plus grande égalité en élargir les expériences formatrices des étudiants, en particulier des classes populaires.

Mots-clés: Éducation à plein temps. Politique publique d'éducation. Contexte scolaire. 
REPD: Há quanto tempo você pesquisa a temática educação em tempo integral (ETI)? A quais grupos de pesquisa está vinculada? Fale um pouco da sua experiência nessa área.

Lúcia Velloso Maurício: Comecei a trabalhar com educação integral em 1983, pelas mãos do Professor Darcy Ribeiro, que me colocou como diretora de escola de Ensino Fundamental, num projeto de Escola de Demonstração, chamado Complexo Educacional de São Gonçalo, município do grande Rio. A participação no projeto e o exercício da gestão me levaram a estudar a proposta de escola de tempo integral e de levantar muitos questionamentos. Por causa disso resolvi fazer mestrado em educação para tentar entender e aprofundar estes questionamentos. Assim a atividade de pesquisa começa a partir de 1986, através do Instituto de Estudos Avançados em Educação da Fundação Getúlio Vargas. Defendi minha dissertação em 1990, com a participação de Darcy Ribeiro na banca, com o título "Por que pixaram a escola - experiência de democratização em escola pública de $1^{\circ}$. Grau ${ }^{5}$. Os Grupos de pesquisa de que participo são NEEPHI - Núcleo de Estudos de Tempos, Espaços e Educação Integral, sediado na Unirio, com participação da UFRJ e UERJ. Participo deste grupo desde 1998, quando ainda estava no doutorado. As criadoras do grupo, além de mim mesma, participamos da implantação dos Cieps no Estado do Rio de Janeiro. Eu dos dois programas de implantação, na década de 80 e de 90 e Ana Cavaliere e Ligia Martha Coelho no II PEE. Este era um grupo de pesquisa e extensão específico sobre escola de tempo integral, mais informações no site do grupo $^{6}$. Participo também do grupo de pesquisa e extensão Vozes da Educação, memórias, histórias e formação de professores, desde 2003, quando ingressei na Universidade do Estado do Rio de Janeiro, na Faculdade de Formação de Professores. É um grupo de pesquisa mais voltado para a memória das escolas e formação de professores.

REPD: Percebe-se que mesmo o eixo de políticas públicas sendo comum nos programas de pós-graduação no Brasil, a ETI fica bastante restrita ao sudeste e sul do país? Sobretudo Rio de Janeiro e Paraná. Por que isso ocorre? Como expandir as pesquisas nesse campo?

Lúcia Velloso Maurício: Veja só... primeiro considerar que o Sul e o Sudeste têm um número muito maior de programas de pós-graduação que as outras regiões do Brasil. Então é natural que qualquer assunto sobressaia nesses programas de pós graduação que são a maioria. Em segundo lugar, o Sudeste e o Sul tiveram experiências de tempo integral muito

\footnotetext{
${ }^{5}$ Publicada parcialmente no artigo "Uma experiência de formação de professores nos anos 80" na Revista Brasileira de Estudos Pedagógicos v. 93, no. 233, 2012.

${ }^{6}$ www2.unirio.br/unirio/cchs/ppgedu/neephi
} 
fortes. Por exemplo, no Rio de janeiro, eu estou falando dos Cieps, mas no Sul, houve um investimento muito forte lá atrás com Brizola, escolinhas chamadas brizoletas, não eram de tempo integral, mas andavam nesse sentido. Ele inaugurou seis mil escolas. No Paraná teve o Jaime Lerner ${ }^{7}$, ex-prefeito de Curitiba, que implantou a política de tempo integral na cidade de Curitiba, na época que era do PDT. Então foram experiências marcantes. Claro, polêmicas, discutíveis, também com marca partidária... lá em Curitiba também era levada pelo PDT. Eu sugiro, para perceber essa concentração de tempo integral na região, um artigo que foi publicado no Em Aberto, número 80, chamado "Duas décadas de educação em tempo integral: dissertações, teses, artigos". Foi escrito por mim junto com a Anelice, ele discute esse assunto, essa tendência, vale a pena dar uma olhada.

REPD: A educação em tempo integral no Brasil passou por diversos períodos históricos com destaque especial para três representados pelos projetos idealizados por Anísio Teixeira na Bahia na década de 1950, por Darcy Ribeiro no Rio de Janeiro nos anos 1980/1990 e a retomada dessa política no ano de 2007 no Governo Lula. Profa Lúcia, fale-nos um pouco desses períodos, a importância de cada um, que aspectos os aproximam e em que se diferenciam.

Lúcia Velloso Maurício: A proposta de Anísio e Darcy têm uma base comum. O Darcy, vamos dizer assim, ele incorporou a proposta que era de Anísio Teixeira. A ideia deles era uma proposta de escola de tempo integral. Eles queriam reorganizar a escola, eles queriam uma escola, uma mudança na estrutura da escola, na pedagogia da escola, na concepção de escola, para que ela fosse voltada para as classes populares, dando acesso a uma diversidade de linguagens, considerando que o fazer também implica em conhecimentos. Tanto a proposta de Anísio Teixeira na década de 50 quanto a de Darcy Ribeiro, os Cieps, em 80/90, elas têm uma base comum ligada à escola. A retomada da proposta de tempo integral em 2007, por mais que os documentos se refiram a Anísio Teixeira e Darcy Ribeiro, já anda em outro sentido. Ela incorpora a proposta do "Cidade Educadora". Ela não muda a escola, ela amplia a carga horária de parte dos alunos da escola. Quando se atende parte dos alunos, você não está reconsiderando, reformatando a escola, isso daí não quer dizer que não possa,

\footnotetext{
${ }^{7}$ Jaime Lerner, político, arquiteto e urbanista brasileiro. Foi prefeito de Curitiba por três vezes e governador do Paraná por duas vezes.

8 O movimento das Cidades Educadoras teve início em 1990 com o I Congresso Internacional de Cidades Educadoras, realizado em Barcelona, na Espanha. Neste encontro, um grupo de cidades pactuou um conjunto de princípios centrados no desenvolvimento dos seus habitantes que orientariam a administração pública a para o desenvolvimento educacional da cidade. Ver Carta das Cidades Educadoras.
} 
vamos dizer assim, trazer benefícios que possam ser incorporados pela escola, para uma transformação da escola, mesmo que só alguns alunos estejam frequentando, mas é muito mais difícil, muito mais distante da integração dos profissionais com os professores. Além do mais, aquela ideia de que este tipo de ampliação vai repercutir em indicadores de qualidade da educação como o Ideb ${ }^{9}$, é completamente fora de foco, porque se você tem uma escola de mil alunos e só cento e cinquenta participam de um programa de ampliação da jornada, a repercussão desses cento e cinquenta no total é muito pequena.

\section{REPD: Uma das concepções que permeiam a ETI no Brasil é o aspecto de política assistencialista. Na sua visão, que aspectos a definem como tal? Esse entendimento traz implicações para as políticas adotadas? Em que sentido isso ocorre?}

Lúcia Velloso Maurício: Isso daí é um assunto bastante complicado porque uma boa parte das pessoas, mesmo a propaganda que se se faz e o senso comum em geral da sociedade, é que você amplia a carga horária da escola, você propõe um tempo integral, para tirar a criança da rua, para você proteger o aluno. Então o que parece vir não é uma demanda pedagógica, é uma demanda para, enquanto o pai está trabalhando, a criança está protegida, a rua está muito violenta, então vamos manter o aluno dentro da escola. De verdade a proposta original não é essa. Não quer dizer que o Darcy e o Anísio desconhecessem o fato de que você, ampliando o tempo, facilita a organização da sociedade, porque os pais se sentem mais tranquilos para ir trabalhar. Eles não desconheciam isso, mas o que eles propunham é que a criança tivesse acesso a conhecimentos, a fazeres e a tecnologias que as crianças filhas de classe média têm frequentando diversas instituições. Na verdade, a criança de classe média tem tempo integral, uma hora está no teatro, outra hora na natação, ou seja em instituições várias. A criança das classes populares, se ela não tiver acesso a determinados bens culturais através da escola, pode ser que ela não tenha acesso nunca, então é esse o sentido. Agora, mesmo que seja uma política lançada com uma predominância do aspecto assistencial, a escola pode entender esse sentido, ela pode transformar o fato de as crianças estarem na escola, mesmo que seja por um aspecto assistencial, aproveitando essa oportunidade e lançar um projeto pedagógico inovador, um projeto pedagógico de ampliação de bens culturais, de ampliação de linguagens, de integração de novos conhecimentos. De uma maneira geral os próprios professores terminam tendo um discurso preconceituoso dizendo “ah, a criança só

\footnotetext{
9 Índice de desenvolvimento da educação Básica
} 
vai pra escola porque tem comida”, "ah, a criança só vai pra escola...” e param aí. A criança pode ir para escola porque tem comida, mas o que ela faz dentro da escola pode ser absolutamente inovador em termos pedagógicos, daí um projeto assistencial pode passar a pedagógico. Essa compreensão é fundamental senão as pessoas vão o tempo todo parar em que a escola está só fazendo atividades assistenciais e o conhecimento, que é a finalidade primeira da escola, não é tratado. Ou seja, a criança pode ir para a escola por um motivo e você pode organizá-la para que o conhecimento seja o objetivo fim.

\section{REPD: Em que medida a Educação Integral poderia resolver a questão do acolhimento de crianças e adolescentes em situação de vulnerabilidade?}

Lúcia Velloso Maurício: Na realidade o objetivo da educação integral não é esse, não é, vamos dizer assim, resolver problemas das crianças em situação de vulnerabilidade, ela pode ser uma consequência. Se você amplia a escola a partir de um projeto pedagógico, e entre seus alunos alguns estão em situação de vulnerabilidade, o fato deles ficarem o dia inteiro na escola oferece a eles outros cenários, outras culturas, outros relacionamentos, que podem, vamos dizer assim, diminuir o impacto da situação de violência em que ele vive. Eu lembro que nos Cieps havia um projeto que se chamava "aluno residente", era uma casa que tinha uma mãe e um pai social, eles podiam aceitar doze meninas e doze meninos. Esses meninos e essas meninas eram alunos da escola, mas estavam numa situação que, por uma circunstância de vulnerabilidade social iam deixar de frequentar a escola, por causa exatamente dessa situação. Então o que se fazia? Você oferecia a essas crianças, em situação de ter que abandonar a escola por conta de risco e vulnerabilidade, uma moradia com pais sociais; eram alunos da escola que pernoitavam, dormiam e tinham relacionamentos com essa mãe e o pai social e com outros companheiros que estavam na mesma situação. Não era como muitos juízes da vara da infância entendiam, não era lugar para acolhimento de marginais, de menores infratores, não era essa a ideia. A ideia era você preservar os alunos que, por uma situação social, iam deixar de frequentar a escola, então era uma proposta de evitar o abandono da escola. Nesse sentido a escola pode colaborar, mas não é seu objetivo primeiro, vamos dizer assim, resolver esse problema. Esse é um problema da assistência social e de outros órgãos do estado. 
REPD: É possível integrar educação para o trabalho (não é educação profissional) na educação de modalidade integral? Se possível qual o melhor modelo vigente em países ocidentais?

Lúcia Velloso Maurício: No projeto dos Cieps não havia uma proposta de educação para o trabalho, mas se você oferece na escola uma diversidade de linguagens e de fazeres, você pode criar habilidades que sejam favorecedoras de uma situação de educação para o trabalho, trabalho com artesanato, trabalho com culinária, trabalhos variados, isso daí cada escola faz o seu projeto, ou seja, o fazer é valorizado, é valorizado como conhecimento. Mas não houve uma experiência específica não. Nos Ciac's ${ }^{10}$ chegou a ter uma proposta nesse sentido, em que houve uma articulação com o Senac, mas não tenho notícias sobre isso.

\section{REPD: Profa Lúcia, encontramos também o fenômeno do preconceito no interior das escolas advindos de diversos segmentos. Na sua experiência com os Ciep, em algum momento esse fenômeno se evidenciou? Como vocês lidaram com isso?}

Lúcia Velloso Maurício: Eu diria que houve situações de preconceito da população em relação ao Ciep's, que foram considerados escola para marginais; de verdade, o aluno do Ciep era discriminado e as pessoas usavam como ameaça "olha, se você não fizer isso, vamos mandar você estudar no Ciep”. Então eu não estou falando de preconceito dentro da escola, estou falando do preconceito da sociedade em relação à própria escola, porque era uma escola de proposta claramente popular e a ideia de oferecer uma escola boa, bem equipada, bem preparada para a população pobre é vista como um desperdício pela sociedade em geral. Havia sim estigma em relação aos alunos, inclusive alimentado por muitos professores e alimentado particularmente pela mídia. Agora, fenômenos de discriminação dentro dos próprios Ciep’s, é possível que tenha ocorrido, como pode ocorrer em qualquer escola. Foram muitas escolas e cada escola, por mais que a gente investisse na formação de todos os funcionários, ela própria é quem encaminha as ações do cotidiano.

\footnotetext{
${ }^{10}$ Inicialmente denominados Centros Integrados de Atenção à Criança e ao Adolescente (CIAC), compunham o Projeto Minha Gente, criado no Governo Collor. Com a coordenação do Ministério da Criança e colaboração da Legião Brasileira de Assistência, foram inspirados nas ideias de Darcy Ribeiro e Brizola que convenceram Collor "da relevância dos CIEPs e da escolaridade em tempo integral.
} 
REPD: Em pesquisas que realizamos um elemento que se evidenciou foi em relação à avaliação da ETI quanto aos resultados obtidos, tanto no processo de implementação, quanto no de desenvolvimento nas escolas. Percebemos que ocorre, muitas vezes, uma avaliação informal, fragmentada, assistemática. Por que razões isso ocorre? Isso pode interferir no investimento em novos programas e projetos? Como melhorar o processo de avaliação e acompanhamento da ETI?

Lúcia Velloso Maurício: Quanto à avaliação, é uma batalha muito grande porque, de fato, de tudo que eu olhei, investiguei, as pessoas não se preocupavam em coletar informações, sistematizar informações sobre possíveis resultados da escola. É muito difícil você formular indicadores objetivos para avaliar o desenvolvimento da educação integral, por quê? Porque a educação integral não quer ver apenas um resultado cognitivo, um resultado intelectual, ela quer ver relações que se façam entre aulas do currículo formal com outras, relações entre pessoas, iniciativas para fazer coisas. A ideia da educação integral é que a pessoa se desenvolva num sentido mais totalizante, que ela tenha acesso à diversidade da cultura e criar indicadores para isso é muito difícil. De fato, do que eu pesquisei, o máximo que as pessoas registravam era a frequência e número de matrícula: matrícula aumenta ou diminui; há evasão, não há evasão; nem mesmo a preocupação em ver o rendimento escolar em relação à ampliação do tempo, nem isso foi olhado com cuidado. Quando você tem todos os alunos da escola funcionando em tempo integral pra desenvolver uma educação integral, então você consegue ter um demarcador: 'até o ano tal, o resultado cognitivo desses alunos, por exemplo, era X; depois do primeiro ano de implantação do projeto, o resultado ficou assim; no segundo ano, no terceiro ano, no quarto ano, no quinto ano'. Esse tipo de sistematização, não conheço lugar em que tenha ocorrido. Indicadores para avaliar a educação integral precisam ser formulados. As pessoas falavam muito, e eu pesquisei no meu pósdoutorado, por exemplo, que os alunos tinham mais iniciativa, que os alunos falavam mais, que os alunos realizavam coisas, que os alunos estavam muito felizes. Um indicador sempre bom é saber se tem algum professor colocou o filho na escola, é um indicador precioso, quando o professor reconhece a qualidade daquela escola para colocar seu próprio filho. Mas a dificuldade é essa, nós ainda não temos indicadores. 


\section{REPD: Um aspecto que ainda nos chama bastante a atenção é em relação aos resultados da ETI na vida dos alunos egressos dos programas e projetos desenvolvidos. Você poderia nos falar um pouco sobre isso?}

Lúcia Velloso Maurício: Se a gente não tem a avaliação da implantação dos projetos, muito menos ainda a gente tem dos egressos. Chamo atenção para a época em que o Jornal O Globo publicou uma semana de matérias sobre os Cieps, quando eles completavam vinte e um anos de funcionamento. Isso foi no ano de 2005. Eu escrevi um artigo sobre a representação social do Jornal O Globo sobre os Cieps, sobre a escola de tempo integral, em que eu analisava exatamente as reportagens que foram citadas, porque elas fizeram um acompanhamento da primeira turma do Ciep, do primeiro Ciep inaugurado, e foram verificar o que que aconteceu com essas pessoas. Só que eles queriam concluir que tudo era ruim, que tudo era o pior possível, e eu, ao longo desse artigo, mostrei que, de fato, você pode concluir o exato contrário do que eles estavam afirmando, é só, vamos dizer assim, discutir com coerência os dados que eles próprios levantaram, mas não era este o objetivo deles.

\section{REPD: Quais são os aspectos mais atuais e relevantes da legislação que trata da educação integral no Brasil?}

Lúcia Velloso Maurício: Bom, após a Constituição e após a LDB, a gente teve o Plano Nacional de Educação de 2001, e temos agora o atual Plano da Nacional da Educação. Tivemos, em 2007, o Decreto "Todos Pela Educação" e tivemos o Fundeb"1. Não vou entrar nos detalhes de cada um, mas vou dizer que o Fundeb foi fundamental, porque previu acréscimo de orçamento por matrícula em escola de tempo integral, isso daí foi uma alavanca importante para ampliar, para espalhar as escolas de tempo integral. Agora, o atual Plano Nacional de Educação propõe na sua meta 6 a ampliação para que o tempo integral seja oferecido em 50\% das escolas no Brasil, abrangendo 25\% das matrículas em escolas públicas. Esta é uma meta ousada, e sendo ousada, às vezes, as pessoas esticam demais a corda para atingir a meta quantitativa e esquecem que o básico é a meta qualitativa, porque na educação integral o que se quer é um novo patamar de qualidade. A gente não quer acumular número de pessoas que passam mais horas na escola. A gente quer um patamar de conhecimento outro que se dê através da escola, que a escola pública em geral está deixando de oferecer

\footnotetext{
${ }^{11}$ Fundo de Manutenção e Desenvolvimento da Educação Básica e de Valorização dos Profissionais da Educação
} 
porque ela tem sido muito mal amparada. Só que o plano foi prejudicado pela aprovação da Emenda Constitucional 95/2016, que congelou o orçamento para todo investimento nos projetos sociais, seja educação, seja saúde, seja assistência social, seja habitação, por vinte anos. Então, essas metas estão condenadas. O Plano propunha que se passasse, até 2024, a investir $10 \%$ do PIB na educação. Com esse congelamento ficou inviável, essas metas não serão cumpridas, além de não poderem ser cumpridas com a qualidade que justifica ter uma escola com tempo maior para poder oferecer uma educação integral.

\section{REPD: Quais são as visões dos/as profissionais da educação pública em relação às políticas de educação integral?}

Lúcia Velloso Maurício: Essa é uma pergunta que... seria um grande achismo e a minha preocupação é que a gente comece a falar da educação, da política de educação integral, da mesmo forma como se falam nas campanhas políticas, na eleição de governador, deputado estadual, deputado federal: todo mundo diz que vai implantar a educação de tempo integral e para aí, nem sabe o que é, qualquer arranjo funciona.

\section{REPD: Quais são os limites e desafios da educação pública, para efetivar com qualidade, as políticas de educação integral no Brasil?}

Lúcia Velloso Maurício: Essa pergunta dá um tratado, mas de qualquer maneira eu vou dar algumas indicações: primeiro orçamento, o orçamento da educação tem que aumentar, esse orçamento não é suficiente para dar educação de forma nenhuma, nem para manter uma educação decente. Em segundo lugar você tem que ter escolas equipadas, professores suficientes, material escolar suficiente, bibliotecas, ou seja, você tem que equipar a escola para que ela funcione. Isso daí é básico, não é para educação integral não, é para qualquer escola. Então: orçamento, equipar a escola, colocar professor suficiente, que esses professores tenham uma formação sempre atualizada, que eles tenham tempo para discutir, para planejar conjuntamente, que eles tenham salário digno. Ou seja, que sejam professores com condições de trabalhar bem. E, por outro lado, os professores precisam querer trabalhar nessa escola, uma escola de educação integral que não é compreendida, ou seja, se o professor não compreende qual é a proposta de educação integral ou a ampliação do tempo para que a 
educação seja integral, se ele não compreende essa proposta, ou se ele discorda dessa proposta, não tem sentido ele estar na escola porque a escola não vai se constituir nesse sentido. Ele pode até chegar lá sem saber e ser incorporado e gostar e trabalhar, mas é indispensável que os professores saibam, discutam, proponham alterações. Outra coisa é que os alunos queiram estar nessa escola. A escola tem que ser agradável, tem que ser convidativa, tudo para que o aluno queira estar na escola, se ele não quiser estar na escola não adianta, não é possível. Não adianta você ter professores que não querem estar lá, não adianta você trabalhar com alunos que não querem estar lá. Em geral, a gente quer estar nos ambientes em que a gente é bem tratado, quando o lugar é interessante, quando é estimulante. A mesma coisa em relação aos pais, os pais precisam confiar na escola, precisam gostar da escola, precisam querer que o seu filho esteja na escola e que ele esteja informado e que eles participem e que eles tenham orgulho. Todas essas coisas que a gente sempre soube né? É isso.

REPD: Para você, na atual conjuntura política do Brasil qual é a função da educação em tempo integral no contexto escolar?

Lúcia Velloso Maurício: Bom, fora as dificuldades todas que eu falei de financiamento, de equipamento, de professor suficiente, de formação, tudo isso, o que eu acho é que a educação em tempo integral no contexto escolar pode favorecer, nesta conjuntura terrível em que nós estamos vivendo, um trabalho coletivo, a educação integral não se faz sem um trabalho coletivo. Então ter tempo e ter espaço para você discutir as ações, para você discutir os projetos, tudo isso é indispensável para você botar em vigor um projeto de educação integral em tempo integral e nisso você organizar um trabalho coletivo.

\section{REPD: É possível mensurar, se tiver dados apresentar, o custo individual do aluno e o custo social da educação integral?}

Lúcia Velloso Maurício: Eu vou dar algumas dicas. A carta 15, revista temática do Gabinete do Senador Darcy Ribeiro, foi completamente dedicada a um relato de como se deu o Segundo Programa Especial de Educação. Um dos artigos, escrito por Tatiana Memória, que administrou o programa, mas que não era uma professora, discorre sobre custo dos alunos. Este relato é um lugar para dar uma noção de custo, mas é muito antigo, dá para ver 
que fatores estavam sendo levados em consideração na composição do custo. A outra coisa que eu recomendo é a página da Campanha Nacional pelo Direito à Educação ${ }^{12}$, que vem batalhando há anos pelo custo aluno-qualidade (CaQi) previsto na $\mathrm{LDB}^{13}$. A Campanha tem um portal ótimo, maravilhoso, é um material formativo de primeira qualidade, explica tudo sobre educação, sobre educação em geral, não é particularmente sobre educação integral. Lá se explica o que é custo aluno qualidade e o que é custo aluno qualidade inicial, ou seja, para você implantar a escola. Você pode inclusive fazer uma simulação de custos a partir da escola ideal para você: eles indicam os fatores que incidem sobre custos, os ingredientes que uma escola tem que ter. É muito interessante e você pode formular, fazer uma simulação da sua escola ideal. Ele compara o valor do custo aluno que apareceu na sua escola ideal com o valor que é distribuído pelo Fundeb, daí você vê a distância.

REPD: Profa Lúcia, certamente deixamos de abordar aqui assuntos interessantes para a discussão da ETI. Sendo assim, fique à vontade para falar a respeito de aspectos que, em sua perspectiva, são relevantes.

Lúcia Velloso Maurício: Eu agradeço a oportunidade de colaborar com estas informações, espero que eu tenha prestado uma ajuda a vocês. Muito obrigada!

12 http://campanha.org.br - http://www.custoalunoqualidade.org.br.

${ }^{13} \mathrm{O}$ artigo "O valor anual mínimo por aluno do FUNDEB, o CAQi e a reserva do possível" de Barbara Cristina Hanauer Taporosky, da UFPR, (publicado na Fineduca - Revista de Financiamento da Educação, Porto Alegre, v. 6, n. 6, 2016) faz análise e descrição desses custos. Disponível em: http://dx.doi.org/10.17648/fineduca-2236-5907-v6-62847. 